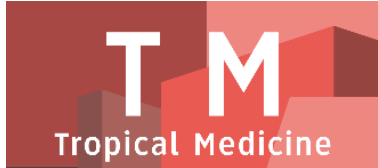

PAPER - OPEN ACCESS

\title{
Formulasi Dan Evaluasi Sediaan Nanoemulsi Gel Vitamin E (Alfa Tokoferol) Sebagai Anti-Aging kulit
}

\author{
Author \\ : Nita Tirmiara \\ DOI \\ : 10.32734/tm.v1i3.270 \\ Electronic ISSN \\ : $2623-0542$ \\ Print ISSN \\ : 2623-0550 \\ Volume 1 Issue 3 - 2018 TALENTA Conference Series: Tropical Medicine (TM)
}

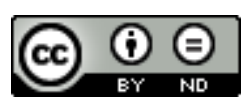

This work is licensed under a Creative Commons Attribution-NoDerivatives 4.0 International License.

Published under licence by TALENTA Publisher, Universitas Sumatera Utara
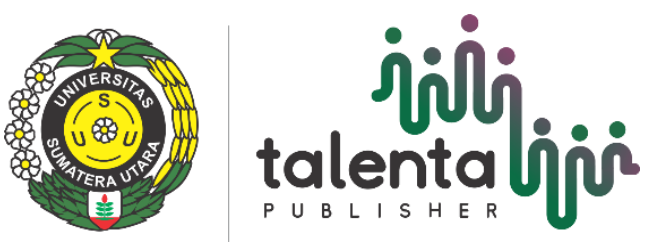


\title{
ن talentaliọi TALENTA Conference Series \\ P U B L I S H E R Available online at https://talentaconfseries.usu.ac.id

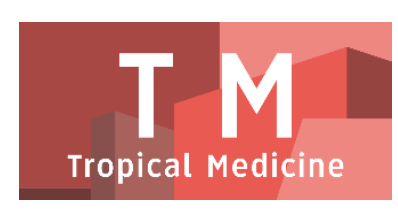 \\ Formulasi Dan Evaluasi Sediaan Nanoemulsi Gel Vitamin E (Alfa Tokoferol) Sebagai Anti-Aging kulit
}

\author{
Nita Tirmiara ${ }^{\mathrm{a}}$, Anayanti Arianto $\mathrm{a}^{*}$, Hakim Bangun ${ }^{\mathrm{a}}$ \\ ${ }^{a}$ DepartemenTeknologiFarmasi, Fakultas Farmasi Universitas Sumatera Utara
}

Email*: anayanti@usu.ac.id

\begin{abstract}
Abstrak
Vitamin E merupakan salah satu bahan yang dapat melindungi kulit dari berbagai kerusakan kulit yang disebabkan radikal bebas seperti kulit menjadi kering dan berkeriput yang dapat menyebabkan penuaan dini. Bentuk sediaan nanoemulsi gel sangat bermanfaat digunakan sebagai anti-aging kulit karena memiliki kestabilan yang tinggi dengan ukuran partikel yang kecil dan penetrasi dari bahan aktif ke kulit yang lebih mudah. Penelitian ini bertujuan untuk memformulasikan vitamin E dalam sediaan nanoemulsi gel dan mengevaluasi aktivitas anti-aging kulit dari sediaan. Nanoemulsi gel diformulasi dalam 3 formula yaitu F1, F2 dan F3 dengan variasi jumlah vitamin E (1\%, 3\%, dan 5\%), sebagai fase minyak adalah minyak zaitun, Tween 80 sebagai surfaktan dan sorbitol sebagai ko-surfaktan dengan basis gel karbopol 940. Evaluasi stabilitas sediaan nanoemulsi gel meliputi uji sentrifugasi, homogenitas, pengukuran viskositas, $\mathrm{pH}$, pengamatan organoleptis dan pengukuran ukuran partikel dan evaluasi aktivitas anti-aging sediaan nanoemulsi gell dari formula terpilih, Semua formula nanoemulsi gel berwarna kuning transparan, stabil selama penyimpanan 12 minggu pada suhu kamar dan formula F3 menunjukkan ukuran partikel yang paling kecil yaitu $129,90 \mathrm{~nm}$ dan 492,93 nm setelah penyimpanan 12 minggu pada suhu kamar dan tetap stabil, sedangkan emulsi gel terjadi pemisahan fase (tidak stabil). Hasil aktivitas anti-aging sediaan nanoemulsi gel lebih baik dibandingkan sediaan emulsi gel dalam hal peningkatan kadar air, pengecilan pori, pengurangan noda dan jumlah keriput pada kulit. Kesimpulan dari penelitian adalah sediaan nanoemulsi gel vitamin E lebih stabil dan memiliki aktivitas anti-aging yang lebih baik dibandingkan dengan sediaan emulsi gel.
\end{abstract}

Kata kunci: Formulasi, Vitamin E, Nanoemulsi gel, Anti-aging

\begin{abstract}
Vitamin $\mathrm{E}$ is one of the ingredients that can protect the skin from various skin damage caused by free radicals such as the skin becomes dry and wrinkled which can cause premature aging. The nanoemulsion gel dosage form is very useful to be used as an anti-aging skin because it has a high stability with a small particle size and penetration of active ingredients to the skin is easier. This aims of the study was to formulate vitamin $\mathrm{E}$ in nanoemulsion gel preparation and evaluate the skin antiaging activity of the preparation. Nanoemulsion gel was formulated in 3 formulas that were F1, F2 and F3 with variations in the amount of vitamin E $(1 \%, 3 \%$, and 5\%), as the oil phase was olive oil, Tween 80 as surfactant and sorbitol as cosurfactant with carbopol 940 gel base Stability evaluation of nanoemulsion gel preparation included centrifugation test, homogeneity, viscosity measurement, $\mathrm{pH}$, organoleptic observation and particle size measurement and evaluation of antiaging activity of gel nanoemulsion preparations from selected formula. All formulas of nanoemulsion gel were yellow and transparent, stable for 12 weeks storage at room temperature and formula F3 show the smallest particle size of $129.90 \mathrm{~nm}$ and $492.93 \mathrm{~nm}$ after 12 weeks storage at room temperature and remain stable, while phase separation occurs in gel emulsion. The results of anti-aging activity of nanoemulsion gel preparations were better than gel emulsion preparations in terms of increasing water content, pore reduction, reducing stains and the amount of wrinkles on the skin. The conclusion of the study is that vitamin E gel nanoemulsion is more stable and has better anti-aging activity compared to gel emulsion preparations.
\end{abstract}

Keywords: Formulation, Vitamin E, nanoemulsion gel, anti-aging

\section{Pendahuluan}

Anti-aging merupakan suatu sediaan atau produk yang berguna untuk mencegah atau memperlambat efek penuaan sehingga terlihat segar, lebih cantik, dan awet muda. Terapi anti-aging akan lebih baik apabila dilakukan sedini mungkin, yakni disaat seluruh fungsi sel-sel tubuh masih sehat dan berfungsi dengan baik [1].

Vitamin E (alfatokoferol) merupakan salah satu antioksidan yang dapat membantu tubuh melawan radikal bebas dan memiliki banyak manfaat untuk kulit antara lain melindungi tubuh dan kulit dari berbagai kerusakan yang disebabkan oleh radikal bebas, membantu melembabkan kulit, memperbaiki elastisitas kulit, dan mengurangi munculnya keriput[2]. 
Sediaan nanoemulsi merupakan sediaan yang lebih stabil karena dengan ukuran globul yang sangat kecil dapat mencegah terjadinya creaming, sedimentasi, koalesens, dan membuat nanoemulsi mendekati stabilitas termodinamik dan lebih menarik dalam hal penampilan fisik serta memiliki efektivitas yang tinggi dalam menembus stratum corneum pada kulit juga dapat mengurangi penyebab penuaan dalamtubuh atau lebih dikenal sebagai anti-aging [3].

\section{Bahan dan Metode.}

Bahan yang digunakan pada penelitian ini adalah Vitamin E, minyak zaitun, Tween 80, sorbitol, metil paraben, propil paraben, karbopol 940, TEA, aqua destilata, span 80, propilen glikol, Gliserin, CMC Na, dapar pH asam 4,01 (Hanna Instrument), dapar pH netral7,01 (Hanna Instrument).

\subsection{Formulasi Sediaan Nanoemulsi Gel}

Tabel 1.Persentase komposisi bahan nanoemulsi gel vitamin E (1,3dan 5\%)

\begin{tabular}{lccc}
\hline \multicolumn{1}{c}{ Bahan Gel } & & Formula (gram) \\
\hline Karbopol 940 & & 5 \\
TEA & & 2 & \\
Aquadest ad & Formula I (gram) & Formula II (gram) & Formula III (gram) \\
Bahan Nanoemulsi & 1 & 3 & 5 \\
Vitamin E & 5 & 5 & 5 \\
Minyak Zaitun & 36 & 36 & 36 \\
Tween 80 & 24 & 24 & 24 \\
Sorbitol & 0,1 & 0,1 & 0,1 \\
Metil Paraben & 0,02 & 0,02 & 0,02 \\
Propil paraben & 100 & 100 & 100 \\
Aquadest & ad & & \\
\hline
\end{tabular}

Pembuatan nanoemulsi gel dengan mencampurkan sediaan nanoemulsi dan basis gel dengan perbandingan tertentu dan di dapat perbandingan yang paling sesuai dari tampilan fisik dan kekentalannya yaitu pada perbandingan 1:4 yaitu masih berwarna kuning transparan dan mudah mengalir. Prosedur pembuatan nanoemulsi gel sebagai berikut :

1. Karbopol 940 ditambahkandengan aquadest dan dihomogenkan di dalam lumpang hingga transparan. Kemudian ditetesi TEA.ddihomogenkan kembali di dalam lumpang (massa 1).

2. Faseminyak :dilarutkan vitamin E dalam minyak zaitun lalu dicampurkan dalam sorbitol.

3. Fase air : dimasukkan metil paraben dan propil paraben dalam aqua destilata kemudian dipanaskan diatas waterbath hingga larut sempurna, setelah itu larutan didinginkan dan kemudian tween 80 dicampurkan kedalam larutan metil paraben dan propil paraben. Fase air diaduk secara manual dengan menggunakan batang pengaduk hingga terbentuk massa yang kental berwarna putih dan selanjutnya fase air di aduk dengan menggunakan magnetic stirrer pada kecepatan 3000rpm.

4. Fase minyak ditambahkan ke dalam fase air. kemudian dihomogenkan dengan magnetic stirrer pada kecepatan 3000 rpm selama \pm 8 jam pada suhu kamar hingga homogen dan terbentuk nanoemulsi yang jernih dan transparan

5. Kemudian sediaan nanoemulsi yang telah terbentuk di sonikasi selama 30 menit (massa 2).

6. Massa 2 dimasukkan ke dalam massa 1 dengan rasio 1:4 dan kemudian dihomogenkan dengan magnetic stirrer pada kecepatan $3000 \mathrm{rpm}$ selama \pm 8 jam pada suhu kamar hingga homogeny dan terbentuk nanoemulsi gel yang jernihdan transparan.

\subsection{Formulasi sediaan nanoemulsi gel}

Komposisi bahan dalam sediaan nanoemulsi gel adalah seperti yang ditunjukkan pada Tabel 2 berikut.

Tabel 2.Komposisi bahan dalam emulsi gel

\begin{tabular}{lcc}
\multicolumn{2}{c}{ Tabel 2.Komposisi bahan dalam emulsi gel } \\
\hline \multirow{2}{*}{ Karbopol 940 } & Bahan gel & Formula (gram) \\
TEA & & 1 \\
Aquadest ad & & 0,4 \\
& Bahan emulsi & 100 \\
\hline Vitamin E & & Formula(gram) \\
MinyakZaitun & 5 \\
Tween 80 & 5 \\
Span 80 & 1,26 \\
\hline
\end{tabular}




\begin{tabular}{lc}
\hline MetilParaben & 0,1 \\
PropilParaben & 0,02 \\
PropilenGlikol & 10 \\
Gliserin & 15 \\
CMC Na & 1 \\
Aquadest ad $(\mathrm{g})$ & 100 \\
\hline
\end{tabular}

Pada proses pembuatan emulsigel, dibuat terlebih dahulu masing-masing komponen gel dan emulsi, selanjutnya kedua komponen tersebut dicampurkan dengan perbandingan sama banyak 1:1.

\subsection{Pengamatan stabilitas sediaan nanoemulsi gel}

Pengamatan stabilitas sediaan dilakukan melalui pengamatan organoleptis secara visual. selama 12 minggu dengan pengamatan setiap 1 minggu sekali. Pengamatan ini dilakukan pada nanoemulsi gel dan emulsi gel yang disimpan pada suhu kamar.

\subsection{Pemeriksaan homogenitas}

Sejumlah tertentu sediaan jika dioleskan pada sekeping kaca atau bahan transparan lain yang cocok, sediaan harus menunjukkan susunan yang homogen dan tidak terlihat adanya butiran kasar

\subsection{Pengukuran $\mathrm{pH}$ Sediaan}

Penentuan $\mathrm{pH}$ sediaan nanoemulsi gel dilakukan dengan menggunakan $\mathrm{pH}$ meter

\subsection{Penentuan viskositas}

Pengukuran ini dilakukan dengan tiga kali pengulangan dengan menggunakan viskometer Brookfield DV-E.

\subsection{Uji sentrifugasi}

Uji sentrifugasi dilakukan pada awal setelah sediaan dibuat dengan pengukuran sebanyak 1 kali. Sediaan dimasukkan ke dalam tabung sentrifugasi kemudian dilakukan sentrifugasi pada kecepatan 3750 rpm selama 5 jam.

\subsection{Penentuan ukuran partikel nanoemulsi gel}

Penentuan ukuran partikel dilakukan di Laboratorium Terpadu Fisika USU Medan menggunakan alat Vasco ${ }^{\gamma}$ CORDOUAN Technologies Particle SizeAnalyzer pada suhu kamar.

\subsection{Pengujian Efektivitas Anti Aging}

Pengujian efektivitas dilakukan untuk formula nanoemulsi F3dan dan formula emulsi gel terhadap sukarelawan sebanyak 6 orang. Semua sukarelawan diukur kondisi awal kulit meliputi kadar air (moisture), pori (pore), dan noda (melanin), dan kerutan (wrinkle) dengan menggunakan skin analyzer.

\section{Hasil dan Pembahasan}

\subsection{Formulasi Nanoemulsi Gel}

Pada penelitian ini dihasilkan sediaannanoemulsi gel vitamin E dengan berbagai konsentrasi dan menghasilkan sediaan yang berwarna kuning transparan dan berbau khas. Formulasi sediaan nanoemulsi gel ini terdiri dari Vitamin E, minyak zaitun, tween 80, sorbitol, metil paraben, propil paraben, karbopol 940, TEA, dan akuades dapat dilihat pada Gambar 1 dan 2 .
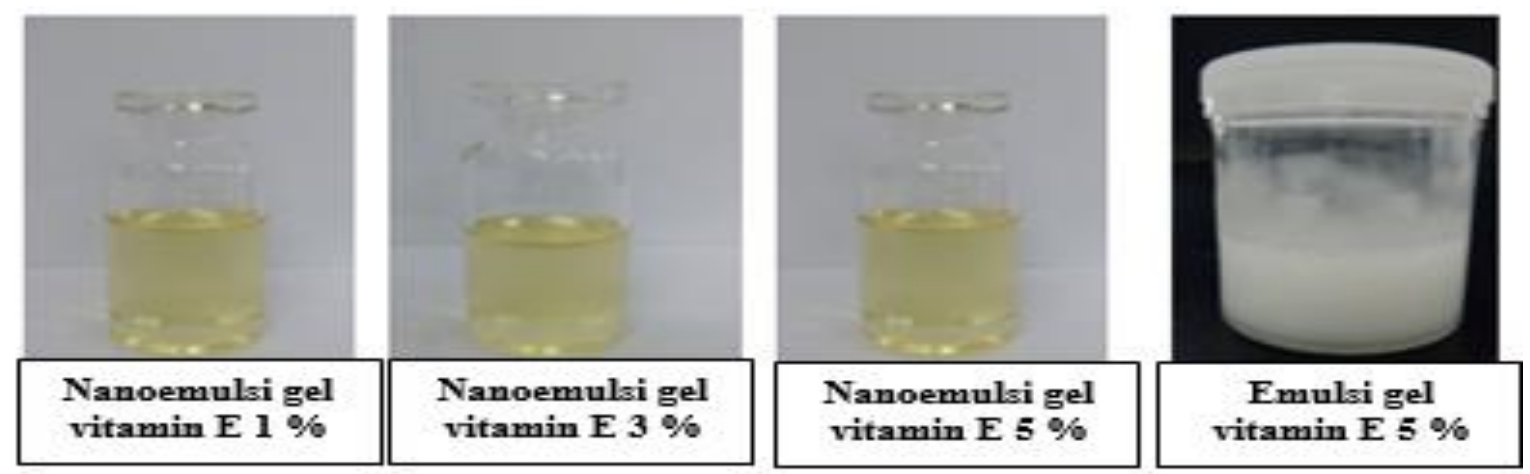

Gambar 1. Sediaan nanoemulsi gel dan emulsi gel sebelum penyimpanan 

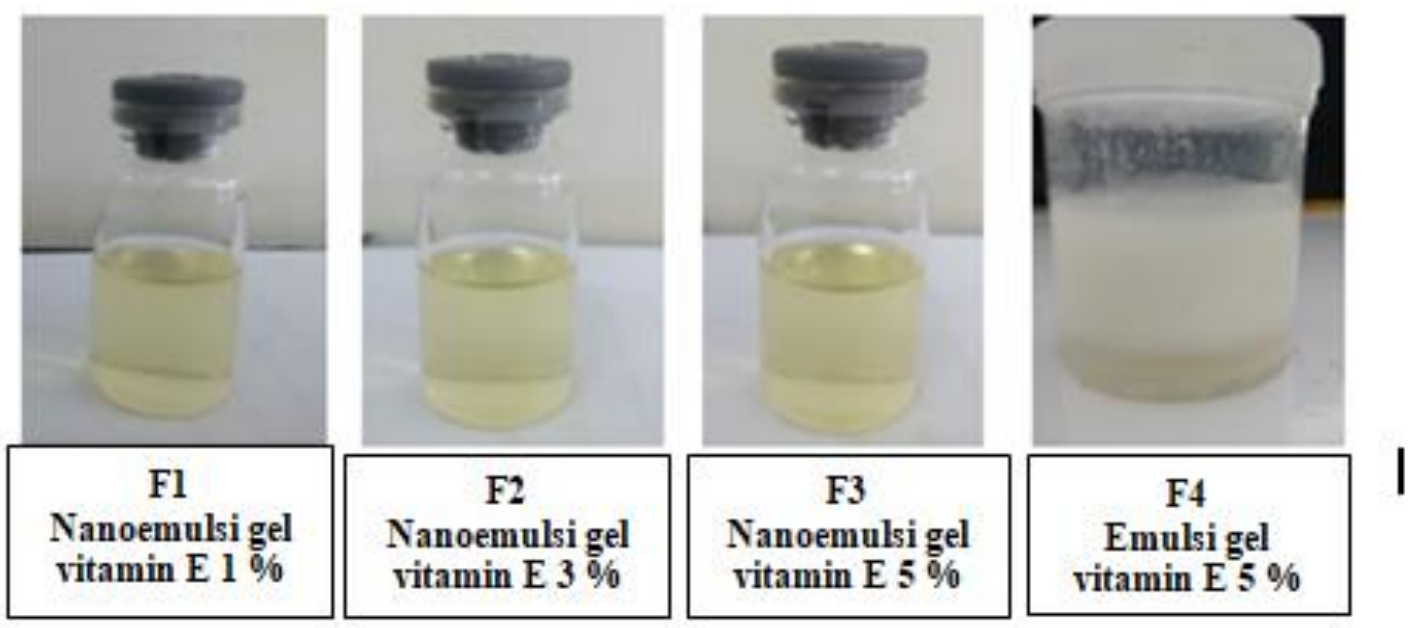

Gambar 2 Sediaan nanoemulsi gel dan emulsi gel setelah 12 minggu penyimpanan pada suhu kamar

Hasil pengujian homogenitas menunjukkan bahwa nanoemulsi gel vitamin $\mathrm{E}$ adalah homogen dan mempunyai pH seperti padaTabel 3 dan emulsi gel padaTabel 4.

Tabel 3.Hasil pengujian $\mathrm{pH}$ dari nanoemulsi gel vitamin $\mathrm{E}$

\begin{tabular}{|c|c|c|c|c|c|c|c|c|c|c|c|c|c|}
\hline \multirow{2}{*}{ Formula } & \multicolumn{13}{|c|}{ waktu (minggu) } \\
\hline & 0 & 1 & 2 & 3 & 4 & 5 & 6 & 7 & 8 & 9 & 10 & 11 & 12 \\
\hline $\mathrm{F} 1$ & 7,0 & 7,0 & 6,8 & 6,7 & 6,7 & 6,7 & 6,6 & 6,6 & 6,5 & 6,5 & 6,3 & 6,2 & 6,0 \\
\hline F3 & 6,8 & 6,8 & 6,8 & 6,8 & 6,7 & 6,7 & 6,6 & 6,5 & 6,5 & 6,5 & 6,4 & 6,3 & 6,3 \\
\hline
\end{tabular}

$\begin{array}{lll}\text { Keterangan : } & \text { F1 } & \text { : Nanoemulsi gel vitamin E konsentrasi 1\% } \\ & \text { F2 } & \text { : Nanoemulsi gel vitamin E konsentrasi 3\% } \\ & \text { F3 } & \text { : Nanoemulsi gel vitamin E konsentrasi 5\% }\end{array}$

Tabel 4.Hasil pengujian $\mathrm{pH}$ dari emulsi gel vitamin $\mathrm{E}$.

\begin{tabular}{|c|c|c|c|c|c|c|c|c|c|c|c|c|c|}
\hline \multirow{2}{*}{ Formula } & \multicolumn{13}{|c|}{ waktu (minggu) } \\
\hline & 0 & 1 & 2 & 3 & 4 & 5 & 6 & 7 & 8 & 9 & 10 & 11 & 12 \\
\hline
\end{tabular}

Pada Tabel 3 dan Tabel 4 menunjukkan bahwa selama penyimpanan semua formula dari sediaan baik nanoemulsi gel maupun emulsi gel yang disimpan pada suhu kamar selama 12 minggu menunjukkan sedikit penurunan $\mathrm{pH}$, namun $\mathrm{pH}$ sediaan masih sesuai dengan $\mathrm{pH}$ kulit yaitu antara 4,5-7,0 sehingga aman digunakan dan tidak menyebabkan iritasi pada kulit.

\subsection{Hasil Penentuan Viskositas}

Data hasil uji viskositas nanoemulsi gel dan emulsi gel vitamin E ditunjukkan pada Tabel 5 dan 6.

Tabel 5. Data uji viskositas nanoemulsi gel (dalam cP)

\begin{tabular}{|c|c|c|c|c|c|c|c|}
\hline \multirow{2}{*}{ Formula } & \multicolumn{7}{|c|}{ Lama penyimpanan (minggu) } \\
\hline & 0 & 2 & 4 & 6 & 8 & 10 & 12 \\
\hline $\mathrm{F} 1$ & 2300 & 2000 & 1900 & 1600 & 1500 & 1000 & 900 \\
\hline $\mathrm{F} 2$ & 2000 & 2000 & 1900 & 1600 & 1600 & 1300 & 1000 \\
\hline F3 & 1800 & 1800 & 1800 & 1600 & 1600 & 1500 & 1300 \\
\hline
\end{tabular}

$\begin{array}{llll}\text { Keterangan } & \text { F1 } & \text { : Nanoemulsi gel vitamin E konsentrasi } & 1 \% \\ & \text { F2 } & \text { : Nanoemulsi gel vitamin E konsentrasi } & 3 \% \\ & \text { F3 } & \text { : Nanoemulsi gel vitamin E konsentrasi } & 5 \%\end{array}$


Tabel 6. Data uji viskositas emulsi gel vitamin E 5\%

\begin{tabular}{lcc}
\hline \multicolumn{1}{c}{ Formula } & Lama penyimpanan (minggu) & Viskositas (cP) \\
\hline Emulsi gel vitamin & 0 & 14500 \\
E 5\% & 2 & 10750 \\
& 4 & 10500 \\
& 6 & 10250 \\
& 8 & 10000 \\
\hline
\end{tabular}

Berdasarkan hasil uji viskositas pada Tabel 5 dan 6 menunjukkan bahwa terjadinya penurunan viskositas sediaan seiring lamanya penyimpanan

\subsection{Hasil Uji Sentrifugasi}
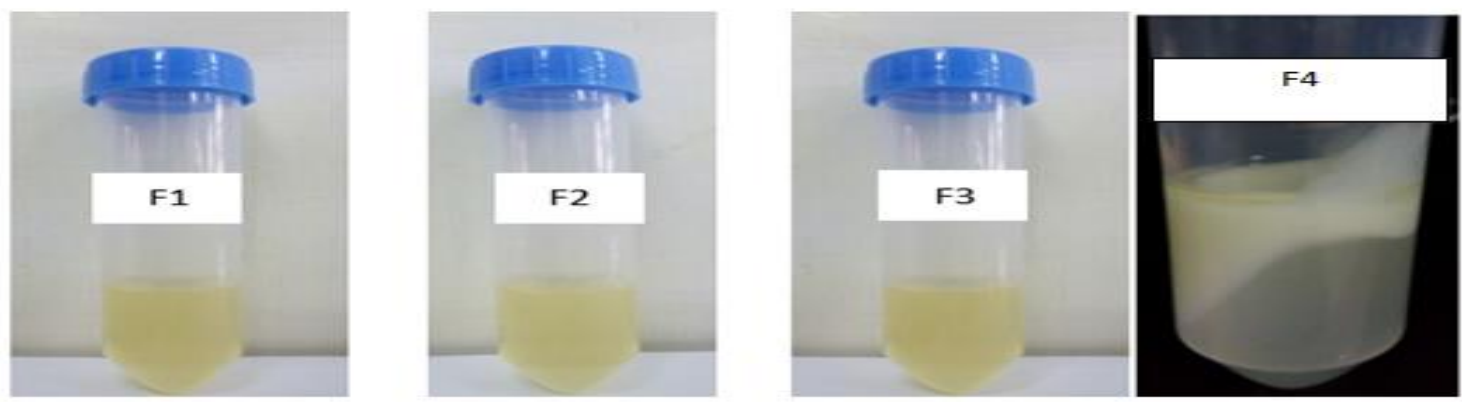

Gambar 3. Hasil uji sentrifugasi sediaan nanoemulsi gel (F1,F2, F3) dan emulsi gel (F4)vitamin E

Setelah dilakukan uji sentrifugasi, sediaan nanoemulsi gel F1, F2 dan F3 menunjukkan tidak adanya pemisahan. Hal ini menunjukkan bahwa formula nanoemulsi gel F1, F2, dan F3 ini stabil selama satu tahun dengan adanya pengaruh gravitasi, sedangkan pada formula emulsi gel terjadi pemisahan fase. Hal ini menunjukkan formula emulsi gel ini tidak stabil dalam satu tahun.

\subsection{Hasil Penentuan Ukuran Partikel Nanoemulsi gel}

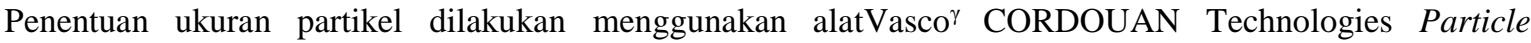
SizeAnalyzer pada suhu kamar. Data hasil penentuan distribusi dan rata-rata ukuran partikel nanoemulsi gel dapat dilihat pada Tabel 7.

\begin{tabular}{cccc}
\multicolumn{4}{c}{ Tabel 7.Data penentuan rata-rata ukuran partikel nanoemulsi gel } \\
\hline \multicolumn{4}{c}{ Rata-rata ukuranPartikel (nm) } \\
\hline Formula & Awal pembuatan & Setelah penyimpanan 6 minggu & Setelah penyimpanan 12 minggu \\
F1 & 421.88 & 500.96 & 699.92 \\
F2 & 256.29 & 481.83 & 577.89 \\
F3 & 129.90 & 321.88 & 492.93 \\
\hline
\end{tabular}

Tabel 7 menunjukkan bahwa sediaan nanoemulsi gel F3 mempunyai ukuran partikel yang lebih kecil bila dibandingkan dengan F1 dan F2 dan seiring penyimpanan ukuran partikel dari semua formula sediaan nanoemulsi gel menunjukkan adanya peningkatan ukuran partikel.

\subsection{Hasil Penentuan Aktivitas Anti-aging Terhadap Sukarelawan}

\subsubsection{Kadar air (Moisture)}

Kadar air diukur pada bagian wajah sukarelawan dan diukur menggunakan skin analyzer Aram. Data hasil pengukuran kadar air (moisture) pada kulit wajah sukarelawan dapat dilihat pada Tabel 8 
Tabel 8.Hasil pengukuran kadar air (moisture) pada kulit wajah (\%)

\begin{tabular}{|c|c|c|c|c|c|}
\hline \multirow[t]{2}{*}{ Formula } & \multicolumn{5}{|c|}{ Lama pemakaian sediaan (minggu) } \\
\hline & 0 & 1 & 2 & 3 & 4 \\
\hline F2 & 26 & 31 & 33 & 37 & 40 \\
\hline \multirow[t]{5}{*}{ (Nanoemulsi) } & 29 & 33 & 35 & 36 & 40 \\
\hline & 35 & 37 & 41 & 44 & 46 \\
\hline & 25 & 28 & 31 & 33 & 37 \\
\hline & 28 & 31 & 33 & 35 & 39 \\
\hline & 33 & 36 & 39 & 41 & 45 \\
\hline Rata-rata & 29,3 & 32,6 & 35,3 & 37,5 & 41,2 \\
\hline \multirow[t]{6}{*}{ Emulsi Gel } & 26 & 28 & 31 & 35 & 36 \\
\hline & 28 & 31 & 33 & 36 & 38 \\
\hline & 33 & 35 & 36 & 39 & 41 \\
\hline & 26 & 28 & 31 & 33 & 35 \\
\hline & 28 & 29 & 33 & 36 & 37 \\
\hline & 31 & 33 & 37 & 39 & 40 \\
\hline Rata-rata & 28,7 & 30,6 & 33,5 & 36,3 & 37,8 \\
\hline
\end{tabular}

Keterangan:

Kering/Normal 37-39\%,

Normal/Normal 39- 59 ,Moist $>60 \%$

\subsubsection{Pori (Pore)}

Besar pori pada kulit wajah sukarelaan diukur menggunakan perangkat skin analyzer yang sama. pada waktu melakukan analisa kehalusan kulit, secara otomatis analisa besar pori ikut terbaca. Data hasil pengukuran pori (pore) pada kulit wajah sukarelawan dapat dilihat pada Tabel 9.

Tabel 9. Hasil pengukuran pori (pore) pada kulit wajah sukarelawan

\begin{tabular}{|c|c|c|c|c|c|}
\hline \multirow[t]{2}{*}{ Formula } & \multicolumn{5}{|c|}{ Lama pemakaian sediaan (minggu) } \\
\hline & 0 & 1 & 2 & 3 & 4 \\
\hline \multirow{6}{*}{$\begin{array}{l}\text { Nanoemulsi } \\
\text { gel (F2) }\end{array}$} & 40 & 38 & 31 & 26 & 24 \\
\hline & 32 & 30 & 27 & 25 & 24 \\
\hline & 29 & 27 & 26 & 25 & 23 \\
\hline & 41 & 37 & 32 & 28 & 25 \\
\hline & 35 & 31 & 29 & 26 & 24 \\
\hline & 30 & 29 & 26 & 24 & 23 \\
\hline Rata-rata & 34,5 & 32 & 28,5 & 25,7 & 23,8 \\
\hline \multirow[t]{6}{*}{ Emulsi gel } & 40 & 38 & 34 & 31 & 29 \\
\hline & 34 & 31 & 30 & 29 & 28 \\
\hline & 31 & 30 & 29 & 27 & 25 \\
\hline & 40 & 37 & 32 & 30 & 29 \\
\hline & 36 & 35 & 32 & 29 & 27 \\
\hline & 30 & 29 & 28 & 28 & 26 \\
\hline Rata -rata & 35,2 & 33,3 & 30,8 & 29 & 27,3 \\
\hline
\end{tabular}

Keterangan:

Membutuhkan perawatan :20-40

Normal $<20$

\subsubsection{Noda (Melanin)}

Noda pada kulit wajah sukarelawan diukur menggunakan perangkat skin analyzer. Data hasil pengukuran noda (melanin) pada kulit wajah sukarelawan dapat dilihat pada Tabel 10

Tabel 10.Hasil pengukuran noda (spot) pada kulit wajah sukarelawan

\begin{tabular}{cccccc}
\hline Formula & \multicolumn{5}{c}{ Lama pemakaian sediaan (minggu) } \\
\cline { 2 - 6 } & 0 & 1 & 2 & 3 & 4 \\
\hline Nanoemulsi & 41 & 38 & 34 & 30 & 28 \\
gel & 39 & 37 & 31 & 28 & 25 \\
(F2) & 36 & 33 & 27 & 23 & 20 \\
& 41 & 39 & 35 & 31 & 29 \\
& 40 & 35 & 32 & 27 & 23 \\
\hline Rata-rata & 38 & 34 & 30 & 25 & 22 \\
\hline Emulsi gel & 39,2 & 36 & 31,7 & 27,3 & 24,5 \\
& 41 & 39 & 34 & 31 & 29 \\
& 39 & 35 & 31 & 29 & 24 \\
& 37 & 34 & 30 & 26 & 32 \\
& 40 & 40 & 37 & 35 & 25 \\
\hline Rata-rata & 39 & 36 & 33 & 28 & 24 \\
\hline
\end{tabular}


Keterangan:

Membutuhkan perawatan (41), Baik(19-40), Normal (<18)

\subsubsection{Kerutan (Wrinkle)}

Keriput atau kerutan pada kulit mata bagian lateral sukarelawan diukur dengan menggunakan perangkat skin analyzer.Data hasil pengukuran Kerutan (Wrinkle) pada kulit wajah sukarelawan dapat dilihat pada Tabel 11

Tabel 11.Hasil pengukuran kerutan (wrinkle) pada kulit wajah

\begin{tabular}{|c|c|c|c|c|c|}
\hline \multirow[b]{2}{*}{ Formula } & \multicolumn{5}{|c|}{ Lama pemakaian sediaan (minggu) } \\
\hline & 0 & 1 & 2 & 3 & 4 \\
\hline F2 & 31 & 29 & 25 & 22 & 19 \\
\hline (Nanoemulsi & 29 & 25 & 20 & 18 & 12 \\
\hline \multirow[t]{4}{*}{ gel) } & 26 & 22 & 19 & 13 & 10 \\
\hline & 32 & 29 & 26 & 23 & 21 \\
\hline & 29 & 27 & 23 & 18 & 14 \\
\hline & 28 & 24 & 19 & 14 & 10 \\
\hline Rata-rata & 29,2 & 26 & 22 & 18 & 12,8 \\
\hline \multirow[t]{6}{*}{ Emulsi gel } & 31 & 30 & 26 & 22 & 19 \\
\hline & 28 & 26 & 23 & 20 & 19 \\
\hline & 25 & 22 & 19 & 17 & 16 \\
\hline & 31 & 29 & 28 & 26 & 24 \\
\hline & 29 & 27 & 24 & 21 & 18 \\
\hline & 25 & 22 & 19 & 17 & 16 \\
\hline Rata-rata & 28,2 & 26 & 23,2 & 20,5 & 18,7 \\
\hline
\end{tabular}

Keterangan:

Membutuhkan perawatan (26-40), Baik(11-25), Normal $(<10)$

Berdasarkan hasil pengukuran aktivitas antiaging diatas menunjukkan bahwa pada formula nanoemulsi gel terjadi perubahan yang lebih baik daripada formula emulsi gel dilihat dari kondisi kelembapan, jumlah pori, jumlah melanin dan kerutan pada kulit setelah 4 minggu pemakaian sediaan nanoemulsi gel.

Hal ini dikarenakan sediaan mengandung vitamin E, yang memberikan perlawanan terhadap kekeringan dan membantu memberikan pelembab natural pada kulit [4].

Selain itu peningkatan kadar air kulit dipengaruhi oleh kemampuan vitamin E dalam melindungi degradasi oksidatif terhadap asam hialuronat [5]. Asam hialuronat berfungi sebagai zat yang mempertahankan kelembapan di dalam kulit. Sedangkan menurut vitamin E sebagai pelembab yang dapat mempertahankan ikatan air di dalam kulit [6].

Teknologi nanoemulsi gel ini juga merupakan metode yang efektif untuk pelepasan vitamin E dan minyak zaitun sebagai f dikarenakan ukuran droplet yang kecil, nanoemulsi gel dapat dengan mudah berpenetrasi melewati lapisan kulit dan dapat meningkatkan penetrasi bahan aktif, sehingga aktivitas kerja minyak zaitun dalam meningkatkan kadar air dalam kulit menjadi lebih efektif [7].

\section{Kesimpulan}

Vitamin E (alfa tokoferol) dapat diformulasikan sebagai sediaan nanoemulsi gel dan stabil selama penyimpanan 12 minggu pada suhu kamar. Sediaan nanoemulsi gel vitamin E dengan konsentrasi 5\% memiliki aktivitas anti-aging yang lebih baik daripada sediaan emulsi gel vitamin E 5\%.ditandai dengan adanya perubahan kondisi kulit pada tiap-tiap parameter aging kulit seperti kadar air (moisture) peningkatan 35\%, kehalusan (evenness) peningkatan 40\%, pori (pore) peningkatan 32,5\%, noda (spot), kerutan (wrinkle) peningkatan 32,5\%.

\section{Daftar Pustaka}

[1] Fauzi, A.R., dan Nurmalina, R. (2012). Merawat Kulit dan Wajah. Jakarta: PT Alex Media Komputindo. Halaman 60, 171

[2] Achroni, K. (2012). Semua Rahasia Kulit Cantik \& Sehat Ada di Sini. Jogjakarta: Javalitera.Halaman 89, 95-96.

[3] Panjaitan, D.T., Budi, P., dan Leenawaty, L. (2008). Peranan Karotenoid Alami Dalam Menangkal Radikal Bebas di Dalam Tubuh. $e$ USU Repository. Halaman 80.

[4] Iskandar, B. (2016). Preparation of Spray Nanoemulsion and Cream Containing Vitamin E as Anti-aging Product Tested in Vitro and in Vivo Method. International Journal PharmaTech Research. 9(6): 307-308.

[5] Loden, M. (2009). Hydrating Substance in Handbook of Cosmetic Science and Technology $3^{\text {rd }}$ Edition. New York : Informa Healthcare USA.107.

[6] Tranggono, R. I., dan Latifah, F. (2007). Buku Pegangan Ilmu Pengetahuan Kosmetik. Jakarta: Gramedia Pustaka Utama. Hal.11-13, 46.

[7] Shah, P.,Bhalodia D., Shelat P. (2010). Nanoemulsion: A Pharmaceutical Review, Sys Rev Pharm: India. 1(1):25-26. 